\title{
Coupling Products and Services in Design Processes: A Case Study of Smart Drip
}

\section{Jyh-Rong Chou', Jih-Lian Ha², and Yi-ShanLai ${ }^{3}$}

${ }^{1}$ Department of Creative Product Design, I-Shou University, Kaohsiung, Taiwan, ROC

${ }^{2}$ Department of Mechanical Engineering, Far East University, Tainan, Taiwan

${ }^{3}$ Department of Creative Product Design, I-Shou University, Kaohsiung, Taiwan, ROC

\section{Abstract}

Design evolution is sequential and progressively associated with industrial and technological developments as well as human lifestyle needs. In response to current design trends toward smart products, this study presents a new perspective on product-service design to facilitate the design of innovative products. The proposed approach focuses on applying TRIZ to developing a physical product associated

Corresponding Author:

Jyh-Rong Chou

jrchou@isu.edu.tw

Received: 29 August 2018

Accepted: 18 September 2018

Published: 11 November 2018

Publishing services provided by Knowledge

(c) Jyh-Rong Chou et al. This article is distributed under the terms of the

Attribution License, which permits unrestricted use and redistribution provided that the original author and source are credited.

Selection and Peer-review under the responsibility of the ICOI-2018 Conference Committee.

\section{G OPEN ACCESS} with its possible service supports to fulfill customers' demands. It is based on the construct that every aspect of product and service quality should be taken into account as a whole in the early design stage. A case study of intravenous infusion(smart drip) design was conducted to demonstrate the applicability of the proposed approach.

Keywords: product-service design, TRIZ, smart product, intravenous infusion, case study

\section{Introduction}

Design is the conscious and intuitive effort to impose meaningful order by taking something from its existing state and moving it to a preferred state, while industrial design is a process of design applied to products that are to be manufactured through industrial production techniques. There are four design evolution phases corresponding to the four times of radical transformation in industry. At the early stage of the Industrial Revolution, people were not used to the machine-made products and some arguments had been proposed in response to the negative social and artistic consequences of the industrial production. "Design for mechanical production" is the first evolution which sought to reform design processes to fit the industrial transformation in machinery and factory production. "Design for mass production" was a critical issue for the second Industrial Revolution in which normalized, standardized, and modularized design advanced the production of large amounts of consumer products 
via the processes of division of labor in an assembly line. With the incredibly fastpaced advances being made in computer and information technologies, automation and digitization had emerged into the mainstream of the third Industrial Revolution. There had been significant progress in industrial design and various design theories and approaches had been proposed in response to the wide application of such new technologies in products and production processes. In addition to computer-aided tools and techniques (e.g., CAD/CAM/CAE, concurrent and collaborative engineering, etc.), human considerations had been involved in various aspects of product or system design. A large number of sophisticated human-focused theories and methodologies had been developed and employed, such as human factors and ergonomics (HF\&E) [1], human-computer interaction ( $\mathrm{HCl})$ [2], usability engineering (UE) [3], Kansei engineering (KE) [4], user-centered design (UCD) [5], interaction design (IXD) [6], universal design (UD) [7], and user experience (UX) design [8].

Design evolution is sequential and progressive associated with industrial and technological developments as well as human lifestyle needs. From the beginning of the 21st century onward, the world has changed radically in a few major steps. New industrial technologies and business models are emerging increasingly and rapidly. Robotics and artificial intelligence (Al), 3D printing, virtual/augmented/mixed reality (VR/AR/MR), social media, mobile networks, cloud platforms, and electronic commerce are changing our lifestyles and affecting the social, economic, and environmental aspects as well. The concept of Industry 4.0 is expected to radically transform industrial production and product value chains as well as business models, which implies that there tends to be a much closer relationship between manufacturing and service industries. Product design and manufacturing can no longer be the only source of competitive advantage and differentiation, whereas service growth in product firms has become one of the most active domains $[9,10]$. This domain is concerned with product firms shifting from designing, developing, and manufacturing products to innovating, selling, and delivering services [11-13].

The term product-service systems (PSS), also known as a function-oriented business model [14], functional sales [15], or functional products [16], is a new concept for businesses to improve their sustainability performance. The key idea behind PSS is that customers do not have specific demand for a product per se, but rather are seeking the utility of the provided product and service. As such, PSS can be defined as the result of an innovation strategy, shifting the business focus from designing and selling physical products only, to selling a system of products and services which are jointly capable of fulfilling the same customers' demands with less environmental impact [17]. Various 
PSS models have been elaborated in which a frequently used categorization of PSS types includes product-orientated, use-orientated, and result-orientated PSS [18.19]. Otherwise, Mont [20] classified PSS into five types: support, sale, use-based, maintenance, and end-of-life (EoL) services. A refined typology of PSS based on functional hierarchy modeling was also proposed by Van Ostaeyen et al. [21], who categorized PSS models according to two distinguishing features: the performance orientation of the dominant revenue mechanism and the degree of integration between product and service elements. Qu et al. [22] conducted a systematic literature review to analyze the state-of-the-art in the field of PSS design, evaluation, and operation methodologies. They concluded that design methodologies in PSS fell into six perspectives, namely: customer perspective, modeling techniques, visualization methods, modularity, TRIZ, and system dynamics, in which the first two were the most commonly-used ones. Annarelli et al. [23] also conducted a comprehensive literature review on PSS to understand the origins, the current state-of-the-art, and the possible future research directions. They found that PSS design is one of the most attractive areas but there has been relatively little research on the exclusive design of PSS in literature. The design process of PSS involves not only the design of a service or a product, but also a whole system including a network of actors and support infrastructure [20].

Industry 4.0 comprises a variety of state-of-the-art technologies (e.g., cyberphysical systems (CPS), RFID, wireless sensor networks, big data, cloud computing, Internet of things (IOT), etc.) to enable the development of a digital and automated manufacturing environment as well as the digitization of the value chain [24].The concepts of CPS and IoT pave the way for design trends toward cyber-physical products $(\mathrm{CPP})$, also referred to as smart products $[25,26]$ or intelligent products $[27,28]$. Although product-service systems (PSS) are regarded as a market proposition that extends the traditional functionality of a product by incorporating additional services [29], most existing PSS design methods support the conceptual design phase at the higher levels of abstraction and the technical design phase strongly lacks for methodical support. This can be explained by the existing challenge of coupling products and services in design processes since these two perspectives focus on different aspects and use specific models which appear as difficult to integrate [30]. In this context, this study proposes a new perspective on product-service design, the purpose of which is to develop a practical approach to facilitate the design and development of innovative products. This approach can be used to assist designers in developing smart products, taking into consideration of the product's functionality and serviceability as a whole. 


\section{Methods}

Various methodologies for supporting PSS design processes have been proposed in the literature [31, 32]. However, most existing methodologies focus on a product's service system design rather than a methodical support for implementing entire product design and development. Responding to the necessity of coupling products and services in design processes, the implementation steps of the proposed approach are elaborated as follows:

\section{Step 1. Identification of needs}

The product-service design involves both the tangible product and intangible service designs in the entire lifecycle. The needs for the product's functionality and serviceability must be identified in order to search for a series of problems that should be resolved to fulfill customers' demands. The functionality aspect mainly focuses on the generation and improvement of the product utility including desired functions and physical appearance, while the serviceability aspect is centered on the maintenance, extension, and enhancement of the product functionality provided through cyber networks.

\section{Step 2. Problem definition}

Product and service design is a goal-directed problem-solving activity aimed at providing practical solutions to satisfy customers' needs. Contradiction problems often occur in a product design process. Song and Sakao [33] also indicated that improvement or enhancement of one service attribute may cause the deterioration of another in the design process of product-service offerings. TRIZ has been recognized as a powerful method for dealing with contradiction problems with application of innovative solutions. The fundamental principle behind the TRIZ method is to find contradictions in a system and then eliminate them by using TRIZ tools. TRIZ has been widely used in the engineering and technical field for R\&D and in the designing for tangible products [34]. The scope of TRIZ has also been extended to non-technical areas, such as marketing, sales, and advertising [35], service design [36-38], and maintenance support [39]. As TRIZ is capable of providing methodical design supports for the performance of functionality and serviceability, it is used as a tool for the proposed approach to define both the functionality- and serviceability-related problems as well as the interdisciplinary problems between the product and service design tasks. 


\section{Step 3. Concept generation}

The aim of TRIZ is to provide designers with a strategic and predictable problemsolving process to advance further in the direction of the specific inventive solution with a minimum number of trial-and-error iterations. The TRIZ problem solving process comprises the following four stages: (1) problem definition; (2) problem classification and tool selection; (3) solution generation; and, (4) evaluation. Problem definition is aimed at clarifying common design questions and involves analytical tasks that are conducted using TRIZ analytical tools. After having finished problem definitions, designers have to classify the problems into categories and then select appropriate tools for the problems. For each problem category, there are some knowledge-based tools available to resolve the problems, such as 39 design parameters and the contradiction matrix, 11 separation principles for physical contradictions, 40 inventive principles for technical contradictions, and 76 standard solutions for substance-field (Sufield) analysis [40]. Traditional TRIZ parameters, principles, and solutions could not be applicable to service design fields since TRIZ tools are originally developed for engineering applications to support technological innovation. To improve the strength of TRIZ application, there are numerous modified TRIZ tools available to resolve the service problems, such as Chang and Lu's service parameters [41], Zhang et al.'s modified inventive principles [42], Jiang et al.'s contradiction parameter options [43], and Gazem and Rahman's interpretation of the 40 inventive principles for performing services [37]. By using the corresponding TRIZ tools, many possible solutions can be generated and then preliminarily evaluated to determine the best solutions to the problems of product, service, and both.

\section{Step 4. Embodiment design}

A product has a physical structure which is assembled from components, subassemblies, and parts into a workable whole. The embodiment design is concerned about the realization of the product concept and the feasibility of its following engineering and manufacturing procedures. It is the process of uniting the imaginary separation between abstract concepts and concrete elements. The embodiment is also used to visually communicate how an intentional function works via the physical structure. In this step, transformation from concepts to elements is accomplished by sketching, 3D modelling, digital mockups as well as 3D-printed prototypes that work for both visual and functional testing. 


\section{Results}

Intravenous (IV) therapy is used to deliver liquid substances directly into a vein. The intravenous route of administration can be used for injections with a syringe at higher pressures or infusions that are usually driven by gravity. Intravenous infusions(also referred to as drips) are used as a popular mode of infusion by which a peripheral venous catheter is placed into a peripheral vein (the vein in the arms, hands, legs, and feet) for intravenous therapy. This is the most commonly used type of IV therapy due to its low cost. However, since there is no assistance from a device, there are more steps involved with the calculation relating to the delivery of any drugs to be administered in this mode. This section presents a case study to demonstrate the applicability of the proposed approach. The case study focuses on developing an innovative smart drip for hospital patients.

\subsection{Identification of needs}

Although the gravity-driven IV infusion remains the most commonly used IV sets in therapy practice, the present design of gravity IV infusion sets has inherent limitations so that that the use of more flexible IV sets would result in an increased safety with their use and a reduction in labor-intensity related to their use and monitoring. In addition to more comfort with their use, more flexible sets could also result in substantial cost savings by saving space and stocking costs. Accordingly, the case study focuses on developing an innovative smart drip to improve current products' functionality and serviceability.

\subsection{Problem definition}

An intravenous infusion is a thin, plastic tube called a catheter that is put into a vein to give a patient fluid. A standard IV infusion set consists of a pre-filled, sterile container (glass bottle, plastic bottle, or plastic bag) of fluids with an attachment that allows the fluid to flow one drop at a time, making it easy to see the flow rate and also reducing air bubbles; a long sterile tube with a clamp to regulate or stop the flow; a connector to attach to the access device; and Y-sets to allow "piggybacking" of another infusion set onto the same line. There are many disadvantages and risks to IV infusion such as fluid overload, air embolism, septicemia, infection, infiltration, phlebitis, thrombophlebitis, hematoma, clotting, pain and discomfort, hypersensitivity reaction, and anaphylaxis. 
Apart from the pathological problems caused by improper use of IV infusion, the main problems of its functionality and serviceability are defined as follows:

1. The IV infusion set is inconvenient for patients to move due to the use of drip stand.

2. It is inconvenient to hang IV bags on a stand connected to the IV line.

3. The long catheter can often messy and can be dangerous while pulling and dragging accidentally.

4. It is important to avoid fluid overload and air embolism when using IV infusion to treat patients.

5. It is inconvenient to regulate or stop the flow by using the clamp.

6. It is difficult for nurses to monitor the patient's condition anytime and anywhere.

7. Are there any functions that can be integrated into the IV infusion set?

\subsection{Problem classification and tool selection}

According to TRIZ contradiction analysis, problems 1 and 2 are classified as physical contradictions and problems 3-6 are considered technical contradictions. Problem 7 involves a functional/serviceable improvement analysis. The two physical contradictions are combined as "An IV infusion set requires a drip stand to generate gravitational potential energy for delivering liquid substances directly into a vein, but the drip stand is inconvenient for users to use (Problem 1-2)". This physical contradiction problem can be resolved using TRIZ separation principles(Separation in system level). The Su-field model is shown in Figure 1.

The attributes of the four technical contradictions were identified and further interpreted according to TRIZ design parameters. The four technical contradiction problems are interpreted as follows:

1. Problem 3 focuses on the improvement of the catheter length (Parameter 3 ) which can produce harmful side effects (Parameter 31 ) and relates negatively to the convenience of use (Parameter 33).

2. Problem 4 attempts to improve energy spent by the IV infusion (Parameter 20) which can produce harmful side effects (Рarameter 31 ). 


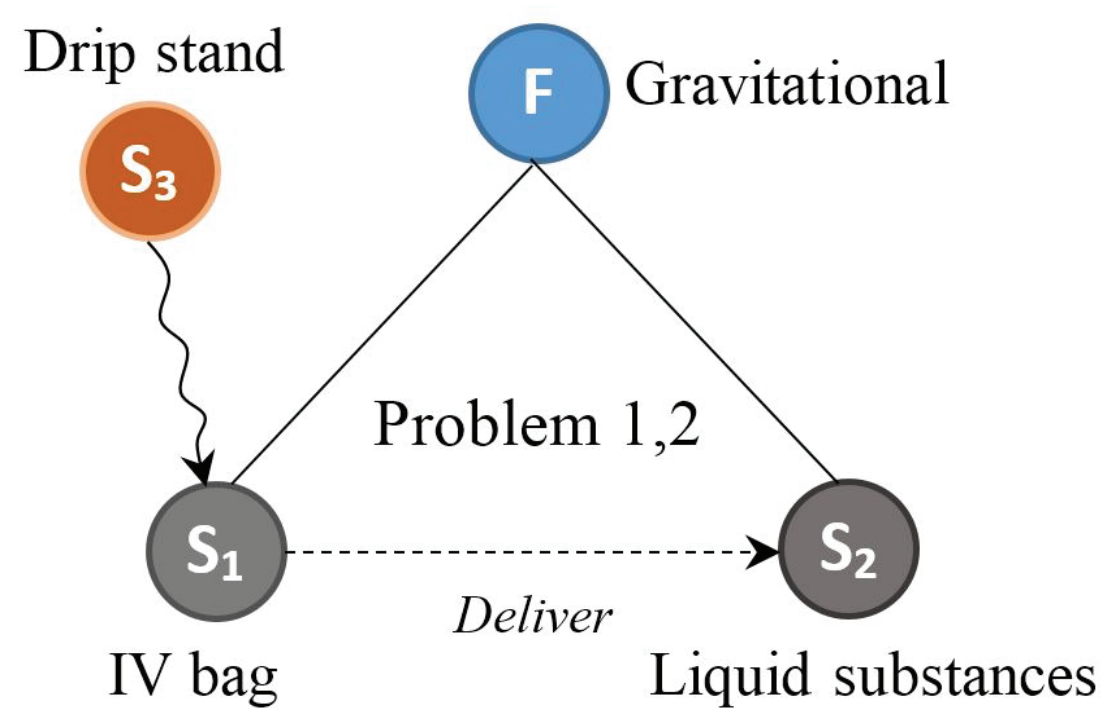

Figure 1: Su-field analysis model for defining Problems 1-2.

3. Problem 5 focuses on improving the stability of the clamp (Parameter 13) which can produce complexity of control (Parameter 37).

4. Problem 6 focuses on improving the level of automation (Parameter 38) which can produce loss of information (Parameter 24).

Problem 7 involves a functional/serviceable improvement analysis. In this problem, the IV infusion set can be regarded as an lot, which is the internetworking of IV infusion set embedded with electronics, software, sensors, actuators, and network connectivity that enable the IV infusion set to share information across platforms as well as to communicate with nursing stations.

\subsection{Idea generation}

The physical contradiction problem is concerned with the use of drip stand to generate gravitational potential energy for delivering liquid substances into a vein. According to the Inventive Principles (\# 5:Merging) for resolving the physical contradiction using "Separation in System Level" method, the drip stand can be merged with the IV infusion set (i.e., gathering things in order to produce or develop a new method or a new service). However, this generates a sub-problem defined as how to produce energy to deliver liquid substances. As shown in Figure 2, the IV infusion set can remove the drip stand and use a mechanical field instead of the gravitational field to drive the fluid of the IV bag to deliver liquid substances directly into a vein (Solution 1-2 for 
functionality).In regard to the serviceability aspect, the IV infusion set is capable of adapting service capacities to meet different patients' demands.

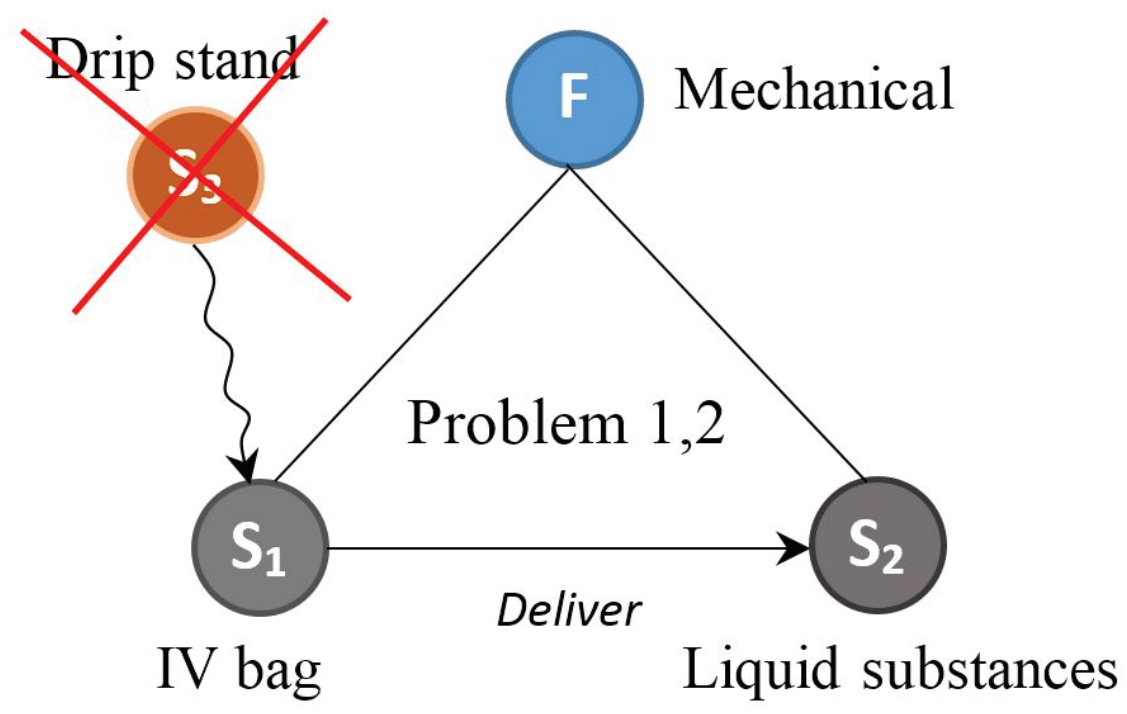

Figure 2: Su-field analysis model for solving Problems 1-2.

The four technical contradiction problems involve functionality and serviceability of an IV infusion set design. The inventive principles extracted from the contradiction matrix and their corresponding TRIZ solutions are presented in Table 1. A total of 6 idea solutions were generated for these contradiction problems as listed below.

\section{Solution 3.1 (Principle 15: Dynamics)}

Functionality: Allow (or design) the characteristics of an object, external environment, or process to change to be optimal or to find an optimal operating condition.

Serviceability: Customer demands usually follow certain pattern. Thus service firms can try to adapt service capacities to meet customer demands.

\section{Solution 3.2 (Principle 17: Moving to another dimension)}

Functionality: Tilt or re-orient the object or system, lay it on its side

Serviceability: Differentiate and segment customers on the basis of their needs, behaviors, ages, etc. 


\section{Solution 4 (Principle 19: Periodic action)}

Functionality: Instead of continuous action, use periodic or pulsating actions.

Serviceability: In the operations of back office, inspections of the working conditions of machines should be regular (periodic) to prevent the accidental breakdown.

\section{Solution 5.1 (Principle 23: Feedback)}

Functionality: Introduce feedback (referring back, cross-checking) to improve a process or an action.

Serviceability: Improve a service by getting feedback from customers and data analysis.

\section{Solution 5.2 (Principle 35: Parameter changes)}

Functionality: Change the physical state of an object or a system.

Serviceability: Focus on adding value to the service environment.

\section{Solution 6 (Principle 33: Homogeneity)}

Functionality: Make objects or systems interacting with a given object or system of the same material (or material with identical properties).

Serviceability: Make a service work with other similar services.

\subsection{Generation of concept solution}

According to TRIZ Inventive Principles given above, the concept solutions corresponding to the defined problems are derived as follows:

\subsubsection{Concept solution 1-2}

Functionality: The IV infusion set is designed to be a wearable device that can be worn on the upper arm as an accessory for IV therapy. It uses a mechanical pump to drive the fluid of the IV bag to deliver liquid substances directly into a vein. 
TABLE 1: Contradiction matrix for the four technical contradiction problems.

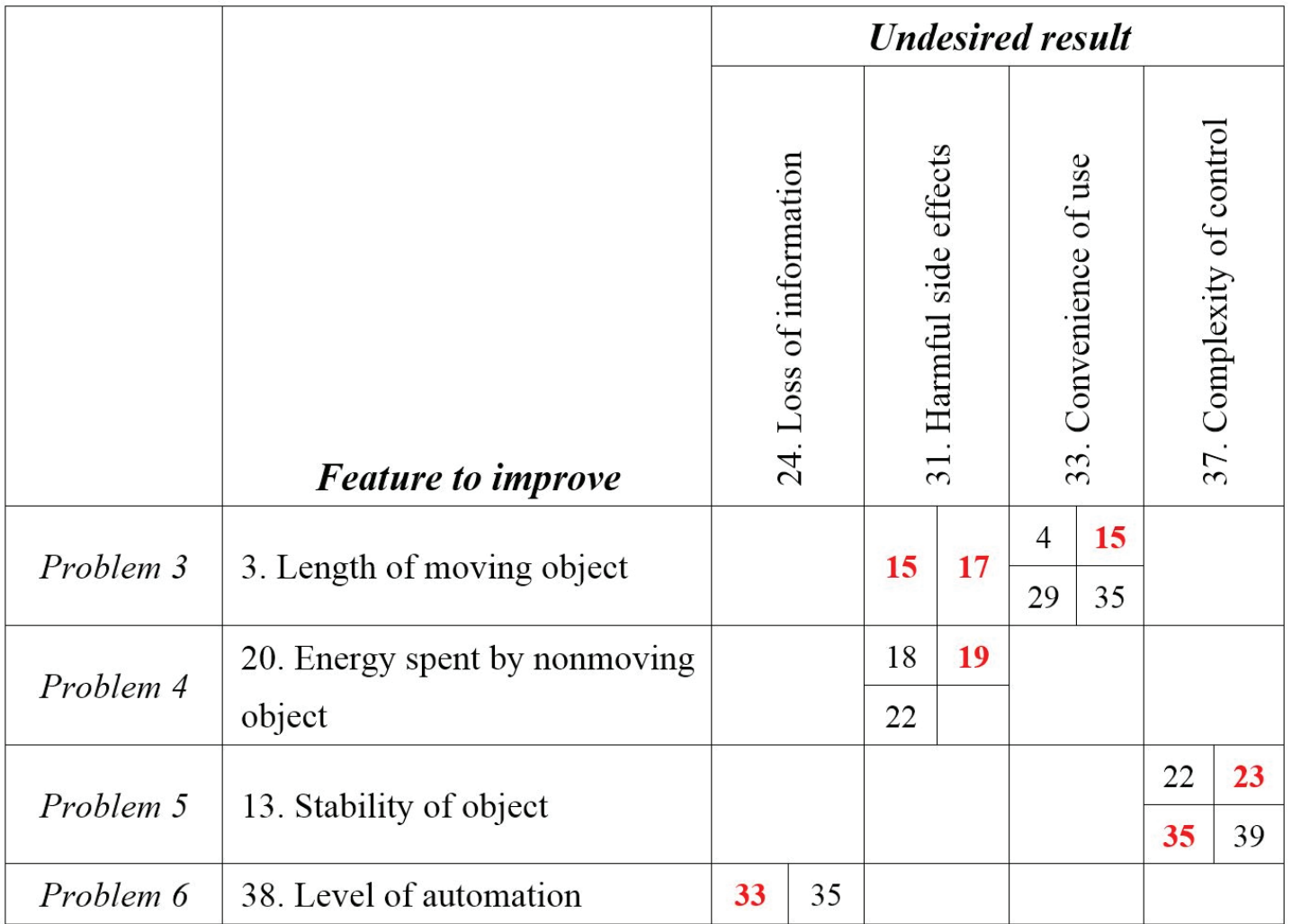

Serviceability: The wearable IV infusion set is capable of adapting service capacities to make services work in parallel with other services; for example, a patient can go to the toilet, go shopping, and take a walk within the hospital without limitations.

\subsubsection{Concept solution 3}

Functionality: The peripheral venous catheter is connected to the wearable IV infusion set and placed into a vein on the hand or arm for intravenous therapy.

Serviceability: The peripheral venous catheter can differentiate patients on the basis of their needs, behaviors, ages, gender, etc.

\subsubsection{Concept solution 4}

Functionality: The IV infusion set uses a peristaltic pump to pump the fluid for flowing one drop at a time, reducing the risk of fluid overload and air embolism.

Serviceability: Inspections of the working conditions of the peristaltic pump can be regular (periodic) to prevent the accidental breakdown. 


\subsubsection{Concept solution 5}

Functionality: The IV infusion set uses an electronic controller to regulate the flow and arrange for the access device.

Serviceability: The IV infusion set can detect the patient's blood pressure and heartbeat to regulate the flow instantaneously.

\subsubsection{Concept solution 6}

Functionality: The IV infusion set includes a digital touch screen that allows the medical staff to check the flow rate and monitor the patient's condition.

Serviceability: The IV infusion set provides security monitoring and emergency call system. When the IV infusion therapy is complete, the infusion system will shut off and recall the nursing staff automatically.

\subsubsection{Concept solution 7}

Functionality: The IV infusion set is rechargeable. It integrates both information and communication technology (ICT) and cloud-based platforms into the IV infusion set, enabling new forms of wearable IV therapy in respect to situated hospital communication, dynamic healthcare models, and dynamic patient differentiation models.

Serviceability: The wearable IV infusion set allows the real-time network connection for communicating the patient's physiological data with nursing stations, and nurses can also monitor the patient's health conditions in any context.

\subsection{Physical embodiment}

According to the concept solutions given above, the wearable IV infusion set was embodied using computer $3 \mathrm{D}$ representations as shown in Figure 3 , and its schematic functionality and serviceability are illustrated in Figures 4 and 5 , respectively.

\section{Concluding Remark}

The concept of Industry 4.ois expected to radically transform industrial production and product value chains as well as business models, which implies that there tends to be a much closer relationship between manufacturing and service industries. Under 

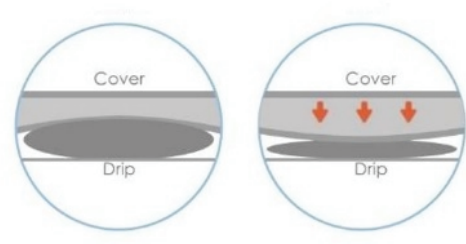

Touch screen

A peristaltic pump to pump the fluid

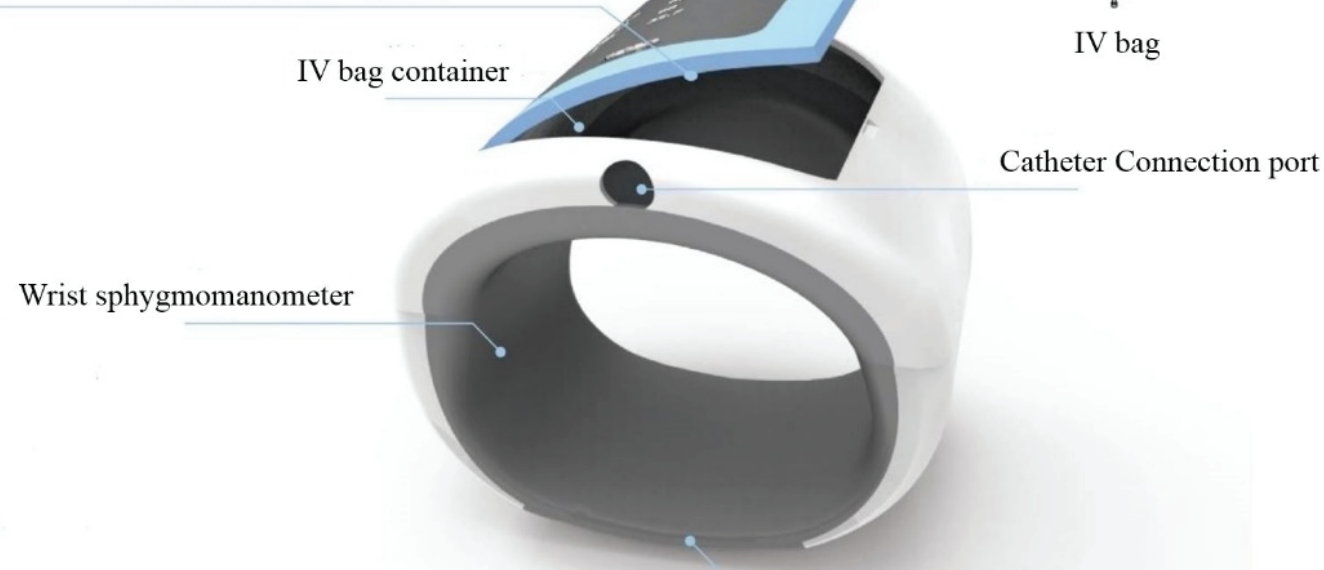

Flexible wristband

Figure 3: Physical embodiment of the wearable IV infusion design.

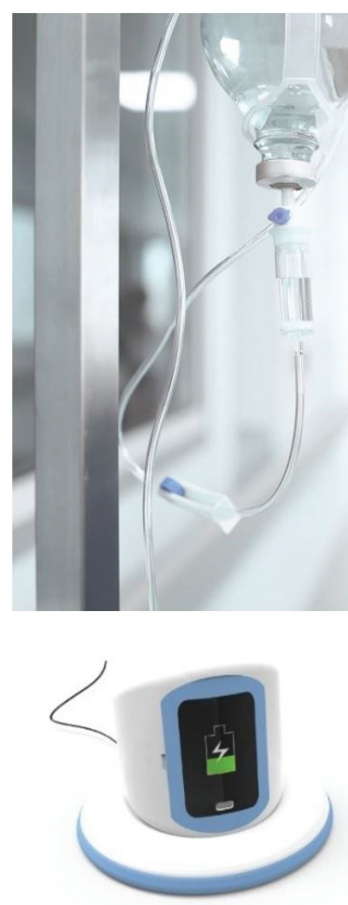

Charging mode
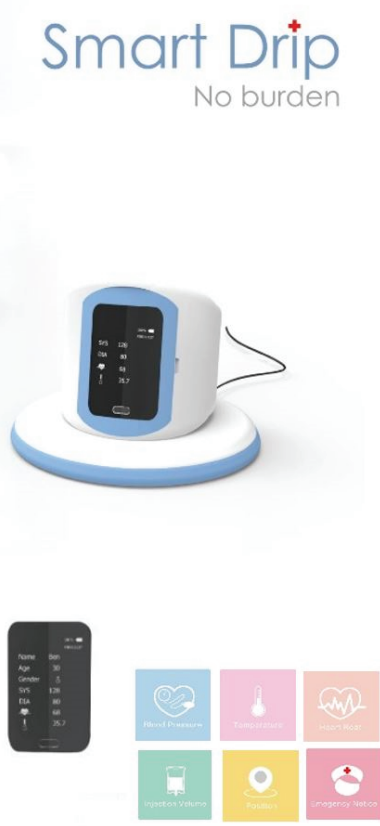

User interface

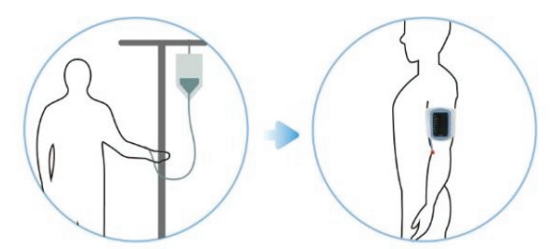

Blood pressure and heartbeat detection
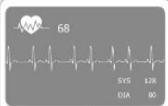

(1)
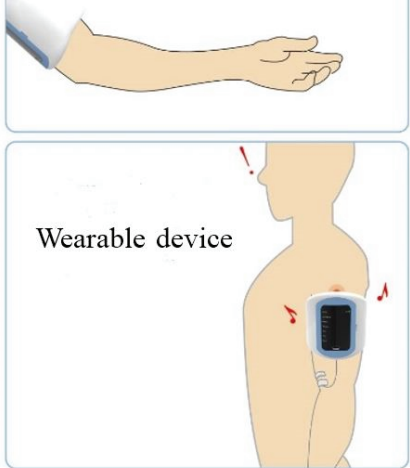

Figure 4: Illustration of the functionality for the wearable IV infusion set. 


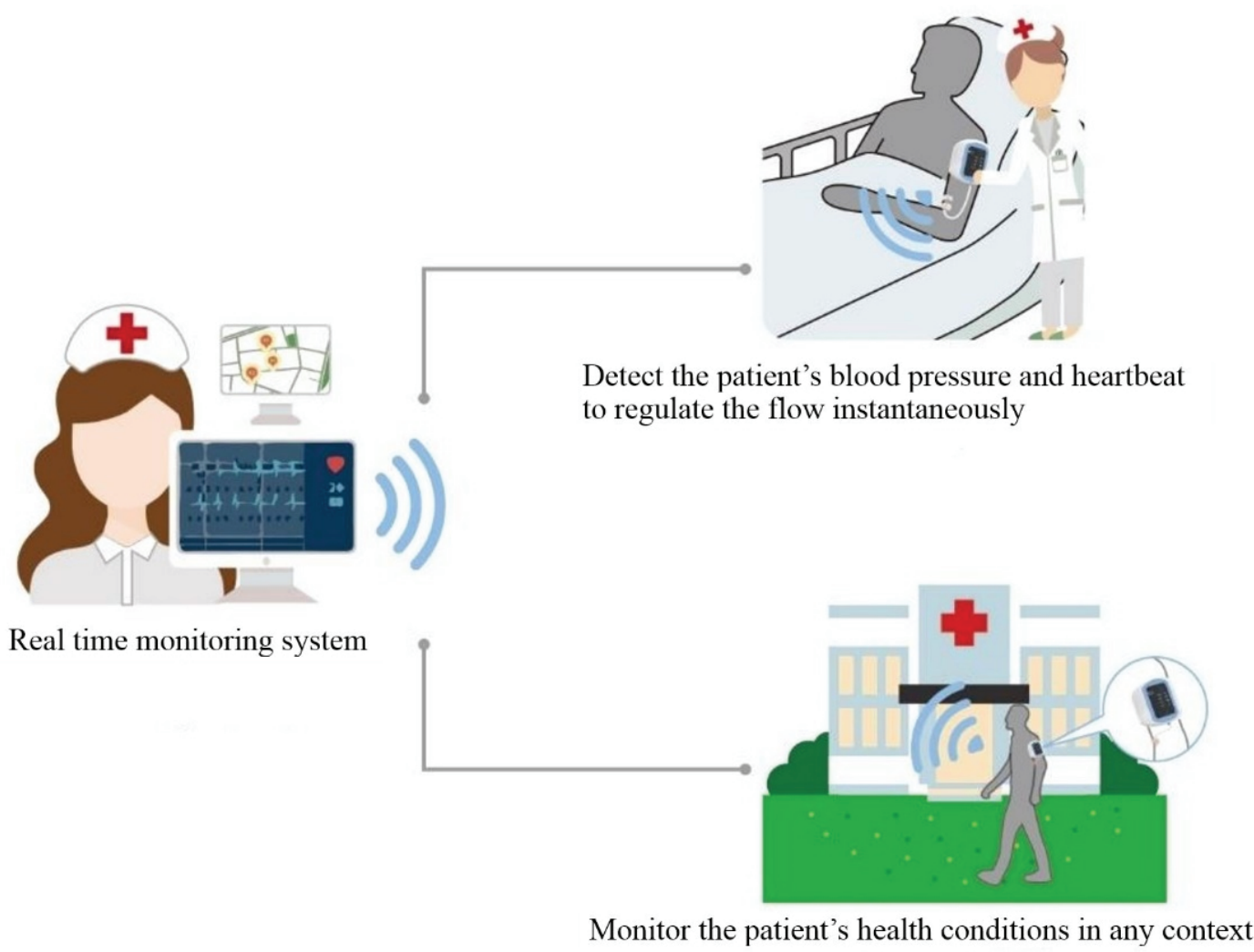

Figure 5: Illustration of the serviceability for the wearable IV infusion set.

the initiative of Industry 4.0, product design can no longer be the only source of competitive advantage and differentiation, whereas service growth in product firms has become one of the most active domains. Although product-service systems (PSS) can be regarded as a market proposition that extends the traditional functionality of a product by incorporating additional services, most existing PSS design methods support the conceptual design phase at the higher levels of abstraction and the technical design phase strongly lacks for methodical support.

TRIZ has been recognized as a powerful method for dealing with contradiction problems with application of innovative solutions. The fundamental principle behind the TRIZ method is to find contradictions in a system and then eliminate them by using TRIZ tools. As TRIZ is capable of providing methodical design supports for the performance of functionality and serviceability of products, it is recommended as a tool for the proposed approach to define and resolve both the functionality- and serviceabilityrelated problems as well as the interdisciplinary problems between the product and service design tasks. To demonstrate the applicability of the proposed approach, a case study concerning the intravenous infusion(smart drip) design was conducted. The results indicate that coupling products and services in design processes is necessary for developing such innovative products. 


\section{Acknowledgements}

This research was financially supported by I-Shou University under grant number ISU107-01-12A.

\section{References}

[1] G. Salvendy, Handbook of human factors and ergonomics, 2nd ed., New York: Wiley, 1997.

[2] M.Helander, T.Landauer, and P.Prabhu, Handbook of human-computer interaction, 2nd ed., New York: Elsevier, 1997.

[3] J.Nielsen, Usability engineering,New York: AP Professional, 1993.

[4] M.Nagamachi, "Kansei engineering: a new ergonomic consumer-oriented technology for product development", International Journal of Industrial Ergonomics, vol. 15, pp. 3-11, 1995.

[5] K.Vredenberg, S. Isensee, and C. Righi, User-Centered Design: An Integrated Approach with CD-ROM, Prentice Hall PTR Upper Saddle River, NJ, USA, 2001.

[6] H.Sharp, Y. Rogers, and J. Preece, Interaction Design: Beyond Human-Computer Interaction, 2nd ed., John Wiley \& Sons, Inc., 2007.

[7] R.L.Mace, Universal design: barrier free environments for everyone, Designers West 33, 147, 148, 150, 152, 1985.

[8] M.Hassenzahl and N. Tractinsky, "User experience-a research agenda", Behaviour and Information Technology, vol. 25, no. 2, pp. 91-97, 2006.

[9] A.L.Ostrom, A. Parasuraman, D.E. Bowen, L. Patrício, C.A. Voss, and K. Lemon, "Service research priorities in a rapidly changing context", Journal of Service Research, vol. 18, no. 2, pp. 127-159, 2015.

[10] C.Kowalkowski, H. Gebauer, and R. Rogelio Oliva, "Service growth in product firms: Past, present, and future", Industrial Marketing Management, vol. 60, pp. 82-88, 2017.

[11] R.Oliva and R. Kallenberg, "Managing the transition from products to services", International Journal of Service Industry Management, vol. 14, no. 2, pp. 160-172, 2003.

[12] H.Gebauer, B. Edvardsson, A. Gustafsson, and L. Witell, "Match or mismatch: Strategy-structure configurations in the service business of manufacturing companies", Journal of Service Research, vol. 13, no. 2, pp. 198-215, 2010. 
[13] W.Ulaga and W. Reinartz, "Hybrid offerings: How manufacturing firms combine goods and services successfully", Journal of Marketing, vol. 75, pp. 5-23, 2011.

[14] M.B.Cook, T.A. Bhamra, and M. Lemon, "The transfer and application of Product Service Systems: from academic to UK manufacturing firms",Journal of Cleaner Production, vol. 14, no. 17, pp. 1455-1465, 2006.

[15] E.Sundin and B. Bras, "Making functional sales environmentally and economically beneficial through product remanufacturing", Journal of Cleaner Production, vol. 13, กо. 9, pp. 913-925, 2005.

[16] J.Lindström, M. Löfstrand, M. Karlberg, and L. Karlsson, "A development process for functional products: hardware, software, service support system and management of operation", International Journal of Product Development, vol. 16, no. 3-4, pp. 284-303, 2012.

[17] E.Manzini and C. Vezzoli, Product-Service Systems and Sustainability-Opportunities for Sustainable Solutions. UNEP (United Nations Environment Programme), Paris, France, 2002.

[18] R.Roy, "Sustainable product-service systems", Futures, vol. 32, no. 3-4, pp. 289-299, 2000.

[19] W.Reim, V. Parida, and D. Örtqvist, "Product-Service Systems (PSS) business models and tactics-a systematic literature review", Journal of Cleaner Production, vol. 97, pp. 61-75, 2015.

[20] O.K.Mont, "Clarifying the concept of product-service system", Journal of Cleaner Production, vol.10, no. 3, pp. 237-245, 2002

[21] J.Van Ostaeyen, A. Van Horenbeek, L. Pintelon, and J.R. Duflou, "A refined typology of product-service systems based on functional hierarchy modeling", Journal of Cleaner Production, vol. 51, pp. 261-276, 2013.

[22] M.Qu, S. Yu, D. Chen, J. Chu, and B. Tian, "State-of-the-art of design, evaluation, and operation methodologies in product service systems", Computers in Industry, vol. 77, pp. 1-14, 2016.

[23] A. Annarelli, C. Battistella, and F. Nonino, "Product service system: A conceptual framework from a systematic review", Journal of Cleaner Production, vol. 139, pp. 1011-1032, 2016.

[24] H.Lasi, P. Fettke, H.-G. Kemper, T. Feld, and M. Hoffmann, "Industrie 4.0", Business \& Information Systems Engineering, vol. 6, no. 4, pp. 239-242, 2014.

[25] R.Schmidt, M. Möhring, R.-C. Härting, C. Reichstein, P. Neumaier, and P. Jozinović, "Industry 4.0-potentials for creating smart products: empirical research results", 
Business Information Systems 208, pp. 16-27, Springer International Publishing, 2015.

[26] M.Abramovici, J.C. Göbel, and H.B. Dang, "Semantic data management for the development and continuous reconfiguration of smart products and systems", CIRP Annals-Manufacturing Technology, vol. 65, pp. 185-188, 2016.

[27] G.G.Meyer, K. Främling, and J. Holmström, "Intelligent products: A survey",Computers in Industry, vol. 60, pp. 137-148, 2009.

[28] P.Leitaõ, A.W. Colombo, and S. Karnouskos, "Industrial automation based on cyber-physical systems technologies: Prototype implementations and challenges", Computers in Industry, vol. 81, pp. 11-25, 2016.

[29] T.S.Baines, et al., "State-of-the-art in product-service systems", Proceedings of the Institution of Mechanical Engineers, Part B: Journal of Engineering Manufacturez21 (10), 1543-1552, 2007.

[30] L.Trevisan, A. Lelah, and D. Brissaud, "New PSS design method of a pneumatic energy system", Procedia CIRP, vol. 30, Pp. 48-53, 2015.

[31] S.Cavalieri and G. Pezzotta, "Product-Service Systems Engineering: State of the art and research challenges", Computers in Industry, vol. 63, no. 4, pp. 278-288, 2012.

[32] B.Doualle, K. Medini, X. Boucher, D. Brissaud, and V. Laforest, "Design of sustainable product-service systems (PSS): Towards an incremental stepwise assessment method", Procedia CIRP, vol. 48, pp. 152-157, 2016.

[33] W.Song and T. Sakao, "Service conflict identification and resolution for design of product-service offerings", Computers \& Industrial Engineering, vol. 98, pp. 91-101, 2016.

[34] L.Chechurin and Y. Borgianni, "Understanding TRIZ through the review of top cited publications", Computers in Industry, vol. 82, pp. 119-134, 2016.

[35] G.Retseptor, "40 Inventive Principles in Marketing, Sales and Advertising", TRIZ Journal, April, 2005.

[36] K.Chai, J. Zhang, and K. Tan, "A TRIZ-based method for new service design", Journal of Service Research, vol. 8, no. 1, pp. 48-66, 2005.

[37] N.Gazem and A.A. Rahman, "Interpretation of TRIZ principles in a service related context", Asian Social Science, vol. 10, no. 13, pp. 108-130, 2014.

[38] C.-H.Lee, Y.-H. Wang, and A.J.C. Trappey, "Service design for intelligent parking based on theory of inventive problem solving and service blueprint", Advanced Engineering Informatics, vol. 29, pp. 295-306, 2015.

[39] T.Vaneker and T. van Diepen, "Design support for maintenance tasks using TRIZ", Procedia CIRP, vol. 39, pp. 67-72, 2016. 
[40] I.M.Ilevbare, D. Probert, and R. Phaal, "A review of TRIZ, and its benefits and challenges in practice", Technovation, vol. 33, pp. 30-37, 2013.

[41] H.H.Chang and P.W. Lu, "Using a TRIZ-based method to design innovative service quality-a case study on insurance industry", Journal of Quality, vol. 16, no. 3, pp. 179-193, 2009.

[42] J.Zhang, K.H. Chai, and K.C. Tan, " 40 inventive principles with applications in service operations management", The TRIZ Journal, December Issues, 2003.

[43] J.C. Jiang, P. Sun, and C.Y. Cheng, "TRIZ contradiction parameter options for service system design (SSD)", Journal of Statistics \& Management Systems, vol. 13, no. 6, pp. 1343-1361, 2013. 